\title{
AC 2009-650: ANALYSIS AND REVISION OF THE "ENGLISH FOR ENGINEERS" PROGRAM AT HERAT UNIVERSITY, WESTERN AFGHANISTAN
}

\section{Beth Richards, University of Hartford}

\section{Keshawarz, University of Hartford}

\section{Hisham Alnajjar, University of Hartford}

Hisham Alnajjar is Associate Dean and Associate Professor, Computer and Electrical

Engineering, College of Engineering, Technology, and Architecture at the University of Hartford 


\section{Analysis and Revision of the "English for Engineers" Program at Herat University, Western Afghanistan}

Background of the partnership

In 2006, the University of Hartford College of Engineering, Technology, and Architecture, in West Hartford, Connecticut began a partnership with the Faculty of Engineering at the University of Herat, in Herat City, Afghanistan. The goals of the project are to use a combination of curriculum revision and development, faculty development, distance learning and collaborative projects, and local/internal partnerships to establish the Herat University Faculty of Engineering at the preeminent Engineering program for Western Afghanistan.

Once a part of Kabul University, the Faculty of Engineering became a permanent part of Herat University in 2004. After functioning in Kabul for approximately 20 years, the Engineering program was closed following the Soviet occupation of Afghanistan in the 1980s. The program temporary relocated to Pakistan in the 1990s. Although the university was officially open in Herat City between 1995 and 2001, programming and resources were extremely limited. Women (and some men) were barred from teaching or attending classes, and significant pressure was exerted on faculty and students to study "appropriate" subjects (that is, Islamic studies).

Even after the change of government in 2001, many constraints remained, including insufficient infrastructure, outdated and poorly integrated curricula (a burdensome mixture of pre- and postSoviet systems), minimal access to updated texts, and a pedagogical approach not geared to critical or independent thinking.

As the Afghan government seeks to rebuild Afghanistan's Higher Education System, it has sought assistance from universities in the United States and Europe, with emphasis placed on information technology, engineering and engineering technology, English language acquisition, faculty professional development, and capacity building.

The partnership between University of Hartford (UH) and Herat University (HU) was accepted for funding by the World Bank in 2006. Its goals were to bring HU engineering instructors to the United States for master's degrees, revise the Civil Engineering curriculum, review the English for Engineers program and develop a technical writing course, and develop technical capacity including lab equipment and computer classroom capability.

Status of the English for Engineers program at HU, summer 2008

Language background

Most Afghans are multilingual, speaking Dari (a dialect of Farsi, or Persian), Pashto, Urdu, Arabic, and at least a few phrases of English. The primary language of Herat Province is Dari. Based on a survey conducted in May 2008, students entering first semester engineering classes at HU have received a wide range of English instruction. The most fluent students (about 20\%) 
studied English beginning in primary grades and continued through high school, for 5 to 6 years of instruction. About 10\% of the students had received one year or less of English instruction. For the remainder of first-semester students, English instruction ranged between 2 and 5 years, with the scale weighted toward the lower end.

When asked what materials they had studied in English classes in secondary school, most replied that they had studied grammar texts and exercises, read ESL books (when available), and listened to radio broadcasts of the BBC.

Civil engineering courses and texts

Classes in the Herat University Faculty of Engineering are conducted in a mixture of Dari and English (for technical terms). However, all textbooks for core courses (geometry and calculus, physics, geology) as well as civil engineering courses (introduction to CE, soil mechanics, concrete and materials) are in English. The only non-English texts used are those for the required courses in Islamic studies. Engineering written examinations are in English.

Students interviewed were clear that they struggled with reading their textbooks, many admitting that they skipped most of the text (because reading it took hours to cover a few pages). They concentrated instead on any graphic materials (figures, equations) and looked up terms in bold or italic (assuming they understood the dictionary definition or were able to select the appropriate "technical" definition from a list of other definitions). Both students and faculty noted that a great deal of class time was devoted to clarifying material in the text (in a mix of Dari and English), resulting in a great deal of lecture about concepts and less time for analysis or application.

Interviews with the dean of the Faculty of Engineering and instructors teaching the English for Engineers classes (English 110, 111, and 210) revealed that instructors were aware of the vast range of English language preparation that students arrived with, but all students had to be placed in one class (about 110 students), due to lack of testing or other assessment to assign them to sections based on skill, as well the lack of instructors to teach multiple sections.

English for Engineers instruction as of summer 2008 was provided by a cadre of recent engineering graduates. These instructors were chosen due to their success in engineering, their English language skills, willingness to teach, and the fact that they had not yet secured engineering work. Most of these instructors used a typical ESL text such as the New InterCom series, which teaches vocabulary, grammar, and basic reading, with content geared to acculturating readers to life in the United States. Each class also used Azar's grammar text for international students. ${ }^{1}$

Class work consisted of discussion of lesson material (brief readings or grammar points), questions from students, instructor clarification of questions, and some written and oral practice. Some classes worked strictly from Azar, with no additional reading material. Pedagogical practices varied slightly, depending on instructor personality and English proficiency. Even though all the instructors emphasized reading comprehension as a primary goal (as stated in 
course descriptions), the texts used and instructor approaches did not consistently support that goal. When asked what they did in class, students invariably replied, "grammar."

Analysis of texts: Reading levels

An analysis of texts being used for first-semester engineering courses and the English texts being studied to prepare students to read these texts revealed a significant disconnect not only in levels of reading difficulty but also in relatedness to engineering subject matter. For example:

Sample A: InterCom 2 reading sample, chapter 1

You're in front of the telephone company. Go up Park Avenue to Main Street and turn right. Walk three blocks and cross York Avenue. What do you see on your right? Now go south on York Avenue to First Street. Turn right and walk two and a half blocks. What's on your left? Now walk east on First Street to University Avenue. Turn right and walk half a block. What's across the street?

Analysis: (10 sentences)

Flesch Reading Ease: 93.9*

Flesch-Kincaid Grade Level: 1.9**

Sample B: Reading sample, Introduction to Engineering text (prepared by Engineer Noor)

Everything we know about the physical world and the principles that govern its behavior has been learned through experiment (observation of phenomena). The ultimate test of any physical theory is its agreement with experimental observations. These observations involve measurement. Some quantities are measured directly and some are found by mathematical relationship.

Analysis: (4 sentences)

Flesch Reading Ease: 16.3*

Flesch-Kincaid Grade Level: 14.1 **

*The Flesch Reading Ease is on a scale of 0-100; the closer to 100, the more readable or comprehensible the material is. In general, scores of 55 or higher indicate material accessible to an "average" US reader.

**The Flesch-Kincaid Grade Level scale indicates the reading level (according to US school grade) needed to comprehend the material.

Despite the sometimes problematic nature of these readability scales ${ }^{2}$, they did provide a broad indicator of the distance between what students were being taught in English classes versus what students needed to read in engineering classes.

The challenge: Developing appropriate texts from materials at hand 
Generic ESL texts do not bridge the gap between basic English skills and competence in reading more challenging texts specific to a profession. In addition, although capacity is slowly being developed (technology as well as print resources) most HU students have limited access to print materials that teach language skills as well as to online sources of these materials. So where to begin?

In this case, it was the library of $\mathrm{HU}$, a hot, dusty room filled with shelves of books that ranged from esoteric studies of baroque instrumental music (donated) to high school literature surveys (also donated) to a small collection of books on reading about basic science concepts in English.

The development of English for Engineers workbooks began, based on three key concepts about language acquisition. Adult language learners:

- want their language acquisition to be immediately applicable for their professional or educational goals

- strongly resist learning material that they do not perceive as applicable or useful

- acquire a new language more proficiently using "old knowledge" as a schema ${ }^{3}$

Using readings on basic scientific concepts

The "starter" text used was D. E. Royd's Beginning Scientific English (BSE). This text was widely used in the 1970s and 1980s to teach English to non-native speakers in science and technology fields. Key to this project were the selected reading texts, which covered concepts such as matter, heat and energy transfer, and water purification-all relevant subjects for civil engineering students. Using BSE as a base, development of a class reader began.

Given the wide range of English language background found in the first-semester English course, the workbook attempted to meet the needs of as many levels of readers as possible. Each chapter began with the original text from BSE, appropriate for the $20 \%$ of students with the highest English language skills (equivalent to above grade 8). The second passage adapted the original text for the lowest level readers (equivalent to primary grades 2-4). A third passage (if needed) adapted the original text for intermediate-level readers (equivalent to grades 5-8).

Keying readings to grammar texts

As of summer 2008, there was no common syllabus or course plan; the only area of agreement was the use of Azar's "blue" and "black" grammar texts. Part of the development of new materials included semester-long course outlines, sample class plans, and a brief instruction manual on how to use the new workbook, for those teaching the classes.

Instructors were encouraged to begin working with the passages by building vocabulary orally, encouraging students to look up unfamiliar words outside class and bring questions to class. Next, the workbook provided an overview of grammar concepts relevant to the particular passage, for example, verb forms, use of pronouns, coordinating conjunctions to link sentences, and so forth. Because of time limits, the workbook did not develop sentence exercises or other reinforcement mechanisms geared to the text. However, it did key the grammar concepts from the reading text to the appropriate section of Azar, which was very familiar to all instructors. 
One outcome from this exercise of linking reading text to grammar concepts was the realization that engineering students did not need to know the full range of, for example, verb forms available in English in order to read a BSE passage. For example the Azar texts, like many grammar books, begin by immersing students in parts of speech or multiple verb forms. However, most passages from BSE contained only present or past (in beginner-level texts) with the addition of passive voice for intermediate texts. To verify that this was representative of texts being read for other courses, an additional analysis of engineering texts was performed. The result: Those texts overwhelmingly used present or simple past and passive voice, as is typical for scientific reporting.

After each reading, the workbook also provided a writing prompt, asking students to complete a short writing passage linked to the text. Obviously, in a class containing more than 100 students, it would be impossible for instructors to provide detailed constructive feedback on writing exercises. However, instructors were encouraged to use these exercises to help students reinforce and apply new vocabulary and grammar concepts as well as use the paragraphs for oral presentation practice in class (a component students consistently clamored for).

Progress as of September 2008

As of September 2008, two workbooks (English 110 and 111 courses) have been completed. The first semester workbook contains 9 reading passages, each with 2 or 3 versions (original and basic; or original, basic, and intermediate), as well as keyed grammar references and a writing prompt. The second semester workbook contains 8 reading passages. Original passages at the intermediate level are used as is, with adaptation for passages that begin at grade 9 level or above. In addition, this workbook contains instructions for writing basic laboratory reports, developed to coincide with the laboratory reports required in science and engineering courses during this semester.

It should be noted that the BSE text occasionally needed updating; nor is it the only text that could be used. However, it met the criteria of being readily available, at no additional cost to the university, which is essential for an entity with a very limited budget or access to materials. Essentially, any U.S. middle-school or high-school science text could be adapted in a similar situation, as well as material available from the Internet.

These workbooks are currently being tested at HU, with instructors encouraged to adapt the texts as needed, as well as document the workbook's successes and shortcomings. A formal assessment has not yet been developed (see below).

Appendix A shows a representative reading passage from the first-semester workbook.

The third-semester workbook, in progress, will use a range of readings, adapted as necessary, and drawn more specifically from "current issues in civil engineering" using material from texts currently used in third-year classes as well as material available through journals and the Internet. Once this text is completed, work will begin on a technical writing text, to use for the course recently added to the civil engineering curriculum. 
Using local capacity—the Herat University English Literature department

Transporting English teachers thousands of miles to assist colleagues is all well and good. But what happens when a) those teachers can't travel (always a possibility given the ongoing unrest in Afghanistan and similar areas) and b) the grant funding expires? A key part of this partnership was to develop local capacity, not just as a buzzword for granting functions but as a reality. The people who live and work and raise their families in Herat City are the ones who should be given the tools to sustain the program, using local resources and, admittedly, minimal budgets.

The English Literature faculty at Herat University quickly became involved in the discussions about the teaching of English (for engineers as well as other academic areas), and provided valuable information about resources available, viable pedagogical approaches, and the department's desire to be of service to the university.

Although this part of the program is in its infancy, the participation of the English Literature faculty promises substantial advantages. Foremost of these is the faculty's exposure to English, as well as their training in reading pedagogy, linguistics, and language acquisition. Although they readily admit their comfort level is in reading literature (a visit to English Literature classes revealed lively discussions about Somerset Maugham, forms of composition, and career aspirations for English-fluent graduates), they are certain they can positively influence the direction and goals of the English for Engineers courses. (A grant is currently being submitted for professional development to augment their teaching of scientific, non-literature texts).

A second advantage to the participation of English Literature instructors is that they live in Herat, teach at the university, and plan to remain there to build careers. They are deeply invested in rebuilding their country and are eager to act as a "service center" for the university.

The challenges of assessment—first semester and beyond

Students are admitted to the HU engineering program based on their performance in secondary schools as well as an entrance examination, which focuses on math, science, and analytical skills. As noted above, there currently is no mechanism in place to assess incoming students' English language skills. Even if such an instrument were available, at this point there is no capacity for teaching leveled sections of the English courses.

During June 2008 the English Literature faculty provided a copy of an entrance exam given to students applying to that program. Interviews with faculty indicated that this entrance exam provided basic information about fluency in English, although they had not been able to correlate scores on the entrance exam to success in the program. The English Literature faculty made this exam available to the English for Engineers program, which is currently reviewing and adapting it to be used as a model for an English for Engineers entrance exam.

Currently, no formal assessment mechanism is in place to evaluate the effectiveness of the firstand second-semester workbooks, although a number of possibilities are being considered, in concert with HU engineering and literature instructors. This is essential not only to evaluate the 
English for Engineers program at HU but also to verify and make it generalizable to other English-language programs that operate under similar restrictions or conditions.

It is clear that, given logistical and financial constraints, any standardized testing (such as TOEFL) is far into the future. However, use of the entrance exam adapted from the English Literature program could be correlated to student grades in the first and second semester. Another possibility is to help the English for Engineers instructors develop comprehensive midterm and final examinations for each course and use those exam results to validate the new course materials.

A third possibility is to develop an assessment mechanism (perhaps modeled on the writing skills portion of ABET) that would evaluate student reading comprehension of engineering texts at the end of the first, second, and third years of the program. Finally, surveys of students and instructors could provide information about whether students are more able to read their texts (greater comprehension, more efficient reading, increased class time for higher level skills and application). Material used in summer 2008 to teach engineering instructors about assessment and evaluation will be adapted in 2009 to help English for Engineers instructors (both from engineering and literature) to begin developing the assessment method(s) that best fit HU's needs.

Conclusion

Although work on the English for Engineers program is in its early stages (active work less than one year old), progress has been made in analyzing the situation and beginning to develop course materials and approaches to teaching that will steadily improve students' reading comprehension. Key to ongoing work will be the development of an assessment mechanism as well as ensuring local capacity is available to continue the work into the future.

\section{References}

1. Azar, B. Understanding and Using English Grammar. Third edition. White Plains, NY: Pearson Education, 1999.

2. Burnett, R. E. Technical Communication. Sixth edition. Boston, MA: Thompson-Longworth, 2005.

3. Bartholomae, L. "Beyond the Methods Fetish. Toward a Humanizing Pedagogy." Harvard Educational Review 64 (1994): 173-194.

The authors thank the Ministry of Higher Education, Islamic Republic of Afghanistan, the U.S. Agency for International Development, and the World Bank for their financial support in funding the partnership between Herat University and the University of Hartford. 
Appendix A

READING \#4

Hard and Soft Water (original passage)

(Reading difficulty: grade level 6.1, advanced beginner)

People say that some water is "hard." When they say this, they mean it does not lather easily and quickly with soap. The reason is it contains very small amounts of calcium compound. This comes from the earth the water flows through.

People say that rain-water is "soft" because it lathers easily and quickly with soap. It does not contain any calcium compound. Water from reservoirs does not usually have much calcium compound in it, but well water often does. So people say that well water is "hard."

When we boil hard water in a pan, a layer of "fur," stays behind. It sticks to the bottom and sides of the pan. Fur is the limestone that the water leaves behind when it changes to steam.

Grammar concepts, Reading \#4

Verb tense review (simple present and past)

Irregular verbs: $2-7$

Adverbs to show time relationships: 5-2

Adverbs A-4

Adverb clauses: $17-1$

Prepositions: A-2

Pronoun: 8-2, 8-3

Other: quotation marks

\section{Writing Exercises, Reading \#4}

- Write a paragraph about the water at home, school, or work. Is it "hard" water or "soft" water? How do you know?

- Write a paragraph about the hard water residue or "fur." What is it? Where else do we find it, besides pans?

\section{READING \#4}

Hard and Soft Water

(Reading difficulty: grade level 4.1, basic)

Some water is called "hard." This means it does not lather easily with soap. Hard water contains very small amounts of calcium. This comes from the rocks in the earth that the water flows through.

Rain-water is "soft." It lathers easily with soap. This is because it does not contain any calcium compound. Water from reservoirs does not contain much calcium. But well water does contain calcium. So well water is "hard." 
When we boil hard water in a pan, it leaves "fur" on the bottom and sides of the pan. Fur is the limestone the water leaves behind when it changes to steam.

Grammar concepts, Reading \#4

Verb tense review (simple present)

Adverbs to show time relationships: 5-2

Adverb clauses: $17-1$

Prepositions: A-2

Pronoun: 8-2, 8-3

Other: quotation marks

\section{Writing Exercises, Reading \#4}

- Write a paragraph about the water at home, school, or work. Is it "hard" water or "soft" water? How do you know?

- Write a paragraph about the hard water residue or "fur." What is it? Where else do we find it, besides pans? 